\title{
Ovarian cancer and oral contraceptives: collaborative reanalysis of data from 45 epidemiological studies including 23257 women with ovarian cancer and 87303 controls
}

Collaborative Group on Epidemiological Studies of Ovarian Cancer*

\begin{abstract}
Summary
Background Oral contraceptives were introduced almost 50 years ago, and over 100 million women currently use them. Oral contraceptives can reduce the risk of ovarian cancer, but the eventual public-health effects of this reduction will depend on how long the protection lasts after use ceases. We aimed to assess these effects.
\end{abstract}

Methods Individual data for 23257 women with ovarian cancer (cases) and 87303 without ovarian cancer (controls) from 45 epidemiological studies in 21 countries were checked and analysed centrally. The relative risk of ovarian cancer in relation to oral contraceptive use was estimated, stratifying by study, age, parity, and hysterectomy.

Findings Overall 7308 (31\%) cases and 32717 (37\%) controls had ever used oral contraceptives, for average durations among users of 4.4 and 5.0 years, respectively. The median year of cancer diagnosis was 1993, when cases were aged an average of 56 years. The longer that women had used oral contraceptives, the greater the reduction in ovarian cancer risk $(p<0.0001)$. This reduction in risk persisted for more than 30 years after oral contraceptive use had ceased but became somewhat attenuated over time-the proportional risk reductions per 5 years of use were $29 \%$ (95\% CI $23-34 \%)$ for use that had ceased less than 10 years previously, 19\% (14-24\%) for use that had ceased $10-19$ years previously, and $15 \%(9-21 \%)$ for use that had ceased $20-29$ years previously. Use during the 1960s, 1970s, and 1980s was associated with similar proportional risk reductions, although typical oestrogen doses in the 1960s were more than double those in the 1980s. The incidence of mucinous tumours (12\% of the total) seemed little affected by oral contraceptives, but otherwise the proportional risk reduction did not vary much between different histological types. In high-income countries, 10 years use of oral contraceptives was estimated to reduce ovarian cancer incidence before age 75 from 1.2 to 0.8 per 100 users and mortality from 0.7 to 0.5 per 100 ; for every 5000 woman-years of use, about two ovarian cancers and one death from the disease before age 75 are prevented.

Interpretation Use of oral contraceptives confers long-term protection against ovarian cancer. These findings suggest that oral contraceptives have already prevented some 200000 ovarian cancers and 100000 deaths from the disease, and that over the next few decades the number of cancers prevented will rise to at least 30000 per year.

\section{Introduction}

Use of oral contraceptives has long been known to reduce the incidence of ovarian cancer., ${ }^{1,2}$ Because ovarian cancer is not common in young women and the incidence increases with age, the public-health effect of this reduction depends mainly on how much the reduced risk persists decades after oral contraceptive use ceases. To investigate the relation between use of oral contraceptives and the subsequent risk of ovarian cancer, data for individual women from 45 epidemiological studies of ovarian cancer ${ }^{1-47}$ have been brought together, checked, and analysed centrally.

\section{Methods}

Identification of studies and collection of data

Epidemiological studies were eligible for this collaboration if they included at least 100 women with ovarian cancer (40 cases in cohort studies) and recorded information on each woman's reproductive history and use of oral contraceptives. Studies were identified from review articles, from computer-aided literature reviews up to January 2006, using Medline, Embase, and PubMed, and from discussions with colleagues. Principal investigators from each eligible study were invited to participate. Of the 48 eligible studies identified $^{1-50}$ (including one multicentre international study $^{25,31,36}$ ) all but three ${ }^{48-50}$ contributed to the collaboration. Individual data could not be retrieved by the investigators from two of these three studies ${ }^{48,49}$ and investigators for the third ${ }^{50}$ could not be located.

Cases were defined as women with malignant epithelial or non-epithelial ovarian cancer and controls were women without ovarian cancer who had not undergone bilateral oophorectomy. Data for individual women were sought from principal investigators of every study on socio-demographic factors, reproductive and menstrual history, use of hormonal contraceptives, use of hormonal therapies for the menopause, height, weight, family history of breast and ovarian cancer, and consumption of alcohol and tobacco. Cohort studies
Lancet 2008; 371: 303-14

See Editorial page 275

See Comment page 277

*Authors listed at end of paper

Correspondence to:

Secretariat, Cancer Research UK Epidemiology Unit, Richard Doll Building, Roosevelt Drive, Oxford OX3 7LF, UK

collaborations@ceu.ox.ac.uk 
were incorporated using a nested case-control design, in which up to four controls were selected at random, matched for follow-up duration, age of the case at diagnosis, and, where appropriate, by broad geographical region. Data provided by investigators were checked and collated centrally so that analyses could be done using definitions as similar across studies as was possible. Apparent inconsistencies in the data were rectified, where possible, by correspondence with the investigators. After the records had been checked and corrected, investigators were sent summary tables and listings of the variables to be used in analyses for final confirmation.

Information on the histological classification of the ovarian cancers had been collected by principal investigators of all but 12 of the 45 participating studies. $1.5,6,10,12,15,16,21,22,26,30,45$ The classification system adopted in each study was used centrally to categorise tumours as epithelial or non-epithelial and, among the epithelial tumours, to categorise them further as clear cell, endometrioid, mucinous, serous, mixed, or other, according to the 10th revision of the International

\begin{tabular}{|c|c|c|c|c|c|}
\hline & Country & $\begin{array}{l}\text { Number of } \\
\text { cases/controls }\end{array}$ & $\begin{array}{l}\text { Median year of } \\
\text { diagnosis }\end{array}$ & $\begin{array}{l}\text { Mean age of } \\
\text { cases (years) }\end{array}$ & $\begin{array}{l}\text { Percent ever-used oral } \\
\text { contraceptives (cases/controls) }\end{array}$ \\
\hline \multicolumn{6}{|l|}{ Prospective studies } \\
\hline \multicolumn{6}{|l|}{13 prospective studies } \\
\hline Oxford/FPA 22 & UK & 49/196 & 1988 & $48 \cdot 1$ & $27 / 67$ \\
\hline $\mathrm{BCCDS}^{40}$ & USA & $365 / 1399$ & 1989 & $65 \cdot 3$ & $20 / 23$ \\
\hline Nurses' Health Study ${ }^{19}$ & USA & $680 / 2720$ & 1991 & $58 \cdot 7$ & $39 / 42$ \\
\hline $\mathrm{RCGP}^{26}$ & UK & $176 / 704$ & 1991 & $52 \cdot 8$ & $49 / 60$ \\
\hline Radiation Technologists ${ }^{45}$ & USA & $41 / 171$ & 1992 & $48 \cdot 2$ & $71 / 75$ \\
\hline Netherlands Cohort ${ }^{46}$ & Netherlands & $253 / 1777$ & 1992 & $67 \cdot 9$ & $14 / 24$ \\
\hline CPS-II Mortality ${ }^{21}$ & USA & 2597/10976 & 1994 & $70 \cdot 2$ & $17 / 21$ \\
\hline CPS-II Nutrition ${ }^{47}$ & USA & $350 / 1405$ & 1997 & $67 \cdot 8$ & $30 / 36$ \\
\hline Southern Sweden ${ }^{38}$ & Sweden & $73 / 288$ & 1997 & $57 \cdot 4$ & $38 / 50$ \\
\hline \multicolumn{6}{|l|}{ EPIC } \\
\hline Spain ${ }^{25}$ & Spain & $33 / 131$ & 1997 & $52 \cdot 9$ & $33 / 39$ \\
\hline Netherlands ${ }^{30}$ & Netherlands & $35 / 140$ & 1999 & $61 \cdot 4$ & $54 / 64$ \\
\hline Oxford ${ }^{36}$ & UK & $55 / 217$ & 2000 & $58 \cdot 7$ & $64 / 57$ \\
\hline $\mathrm{WLH}^{41}$ & Norway/Sweden & 99/399 & 1998 & $49 \cdot 3$ & $81 / 85$ \\
\hline NOWAC ${ }^{39}$ & Norway & $105 / 420$ & 2000 & $59 \cdot 8$ & $25 / 33$ \\
\hline Million Women Study ${ }^{27}$ & UK & $2815 / 11258$ & 2001 & $60 \cdot 2$ & $48 / 56$ \\
\hline All prospective studies & 6 countries & $7726 / 32201$ & 1998 & $63 \cdot 7$ & $34 / 39$ \\
\hline \multicolumn{6}{|l|}{ Case-control studies } \\
\hline \multicolumn{6}{|c|}{19 case-control studies, with population controls } \\
\hline Casagrande/Pike ${ }^{2}$ & USA & $150 / 150$ & 1974 & $40 \cdot 2$ & $43 / 40$ \\
\hline Weiss ${ }^{5}$ & USA & $319 / 751$ & 1976 & $54 \cdot 8$ & $15 / 27$ \\
\hline $\mathrm{Nasca}^{7}$ & USA & $403 / 714$ & 1978 & $54 \cdot 8$ & $19 / 21$ \\
\hline Cramer $^{6}$ & USA & $248 / 238$ & 1979 & $51 \cdot 5$ & $17 / 23$ \\
\hline $\mathrm{CASH}^{8}$ & USA & $573 / 4228$ & 1981 & $41 \cdot 9$ & $52 / 64$ \\
\hline Whittemore $^{9}$ & USA & $215 / 646$ & 1984 & $50 \cdot 8$ & $47 / 56$ \\
\hline Shu/Brinton ${ }^{13}$ & China & $229 / 229$ & 1985 & $48 \cdot 4$ & $13 / 7$ \\
\hline Western New York ${ }^{37}$ & USA & $123 / 696$ & 1988 & $58 \cdot 6$ & $17 / 30$ \\
\hline Risch $^{17}$ & Canada & $450 / 564$ & 1991 & $56 \cdot 7$ & $39 / 50$ \\
\hline Green/Purdie ${ }^{20}$ & Australia & $793 / 855$ & 1992 & $55 \cdot 2$ & $49 / 64$ \\
\hline Mosgaard $^{24}$ & Denmark & 915/1099 & 1992 & $46 \cdot 0$ & $65 / 77$ \\
\hline Cramer $\|^{28}$ & USA & $564 / 525$ & 1993 & $51 \cdot 2$ & $45 / 55$ \\
\hline $\operatorname{Riman}^{34}$ & Sweden & $808 / 3897$ & 1994 & $61 \cdot 5$ & $28 / 29$ \\
\hline German OCS ${ }^{35}$ & Germany & $282 / 533$ & 1995 & $55 \cdot 2$ & $34 / 51$ \\
\hline Pike/Wu ${ }^{42}$ & USA & $477 / 660$ & 1995 & $55 \cdot 5$ & $54 / 63$ \\
\hline Goodman/Wu $u^{33}$ & USA & $720 / 892$ & 1996 & $55 \cdot 0$ & $39 / 54$ \\
\hline NISOC Study ${ }^{32}$ & Israel & $1351 / 2264$ & 1996 & $56 \cdot 6$ & $20 / 23$ \\
\hline OVCARE $^{43}$ & USA & $320 / 1412$ & 1996 & $45 \cdot 5$ & $79 / 88$ \\
\hline \multirow[t]{2}{*}{ SHARE $^{29}$} & USA & $767 / 1367$ & 1996 & $51 \cdot 6$ & $47 / 62$ \\
\hline & & & & & (Continues on next page) \\
\hline
\end{tabular}




\begin{tabular}{|c|c|c|c|c|c|}
\hline \multicolumn{6}{|c|}{ (Continued from previous page) } \\
\hline \multicolumn{6}{|c|}{13 case-control studies, with hospital controls } \\
\hline Newhouse $^{1}$ & UK & $289 / 582$ & 1973 & $54 \cdot 1$ & $7 / 11$ \\
\hline McGowan $^{3}$ & USA & 196/197 & 1975 & $49 \cdot 9$ & $21 / 28$ \\
\hline Paffenbarger ${ }^{10}$ & USA & $111 / 481$ & 1975 & $55 \cdot 4$ & $23 / 21$ \\
\hline Hildreth/Kelsey ${ }^{4}$ & USA & $62 / 1068$ & 1978 & $60 \cdot 1$ & $5 / 11$ \\
\hline Hartge $^{12}$ & USA & 296/334 & 1979 & $54 \cdot 4$ & $25 / 23$ \\
\hline Booth $^{11}$ & UK & 233/441 & 1980 & $51 \cdot 5$ & $16 / 26$ \\
\hline \multicolumn{6}{|l|}{ WHO } \\
\hline Developed $^{14}$ & Australia, GDR, Israel & 202/3862 & 1982 & $41 \cdot 4$ & $29 / 48$ \\
\hline Developing $^{14}$ & 8 countries* & $431 / 14869$ & 1983 & $39 \cdot 3$ & $22 / 34$ \\
\hline Rosenberg $^{18}$ & USA & $960 / 3828$ & 1983 & $49 \cdot 6$ & $15 / 19$ \\
\hline Negri/Franceschi $i^{15}$ & Italy & $976 / 2494$ & 1986 & $53 \cdot 1$ & $7 / 10$ \\
\hline $\mathrm{PEDS}^{23}$ & USA & $411 / 1718$ & 1989 & $54 \cdot 6$ & $33 / 32$ \\
\hline Tzonou/Tricopoulos ${ }^{16}$ & Greece & $339 / 447$ & 1990 & $56 \cdot 2$ & $2 / 6$ \\
\hline Negri $^{31}$ & Italy & $1031 / 2411$ & 1995 & $54 \cdot 9$ & $11 / 11$ \\
\hline Zhejiang-Curtin ${ }^{44}$ & China & $287 / 650$ & 1999 & $46 \cdot 3$ & $24 / 36$ \\
\hline All case-control studies & 18 countries & $15531 / 55102$ & 1992 & $52 \cdot 4$ & $30 / 37$ \\
\hline \multicolumn{6}{|l|}{ Total } \\
\hline All 45 studies & 21 countries & $23257 / 87303$ & 1993 & $56 \cdot 1$ & $31 / 37$ \\
\hline
\end{tabular}

Classification of Diseases (ICD10).${ }^{51}$ Whenever possible epithelial tumours were further categorised as to whether they were borderline malignant or fully malignant. ${ }^{51}$

\section{Defining oral contraceptive use}

Principal investigators of every participating study had collected information on whether individual women had ever used oral contraceptives, and most had also collected information on total duration of use, age at first and last use, and calendar year of first and last use. The cases had been diagnosed with ovarian cancer on average about 20 years after they had first used oral contraceptives. Validation studies have shown that, although women were able to recall whether or not they took oral contraceptives in the past, their ability to recall reliably which preparations they used declined soon after use ceased. ${ }^{52}$ There is, however, a strong relation between calendar year of use and the dose of oestrogen in the oral contraceptives typically used. ${ }^{29,53,54}$ In the USA and UK, for example, the oral contraceptives prescribed before 1970 were typically high-dose preparations, often containing $100 \mu \mathrm{g}$ or more of oestrogen; between 1970 and 1980 prescriptions were typically for medium-dose preparations containing about $50 \mu \mathrm{g}$ of oestrogen; and by 1980 most prescriptions were for low-dose preparations, containing $30 \mu \mathrm{g}$ or less of oestrogen..$^{33,54}$ Calendar year of oral contraceptive use could therefore be taken, at least roughly, to be a proxy for oestrogen dose and women were classified according to the mid-year of use (before 1970, 1970-79, and 1980 or after) to correspond to likely use of high-dose, medium-dose, and low-dose preparations. Sensitivity analyses were done, also classifying women by the calendar year of first and last use. Although most studies did not distinguish between oral contraceptives containing oestrogen-progestagen combinations and preparations containing progestagens only, more than $95 \%$ of oral contraceptives used in these populations would have been of the combined type. ${ }^{55}$

\section{Statistical analysis and presentation of results}

The statistical methods were similar to those used when analysing the worldwide data for the effects of oral contraceptives on breast cancer. ${ }^{55}$ Data from different studies were combined by means of the Mantel-Haenszel stratification technique, the stratum-specific quantities calculated being the standard "observed minus expected" (O-E) numbers of women with ovarian cancer, together with their variances and covariances. ${ }^{55-57}$ Use of these simple stratified O-E values has the advantage of avoiding assumptions about the precise forms of any relations in the data. The stratified O-E values, together with their variances and covariances, yield both odds ratios (subsequently referred to as relative risks) and associated p values. When two groups only are compared, relative risk estimates are obtained from the O-E value and its variance $(\mathrm{V})$ by the one-step method $^{56,57}$ as are their standard errors (SE) and CIs. The actual formulae are: $\log$ relative risk $=(\mathrm{O}-\mathrm{E}) / \mathrm{V}$; and its variance $=1 / \mathrm{V}$. When more than two groups are compared, variances are estimated by treating the relative risks as floating absolute risks (FARs). ${ }^{58}$ This 


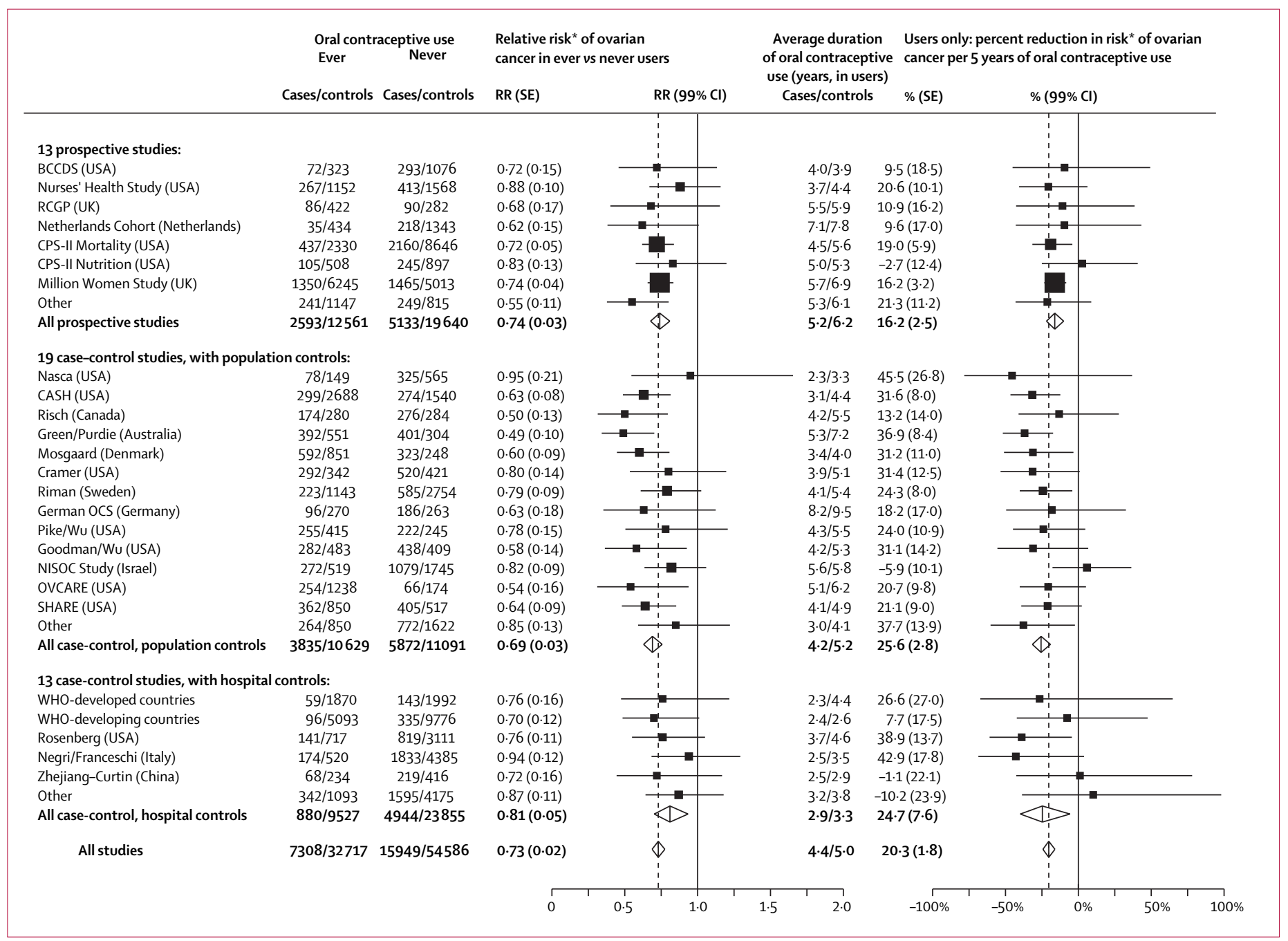

Figure 1: Details of and results from studies contributing data for oral contraceptive use and ovarian cancer Dotted lines represent overall result for all women. *Stratified by study, age, parity, and hysterectomy.

approach yields floated standard errors (FSE) and floated confidence intervals (FCI). The use of floating absolute risks rather than conventional methods does not alter the relative risks but slightly reduces the variances attributed to the relative risks that are not defined as $1 \cdot 0$. This method enables valid comparisons between any two exposure groups, even if neither is the baseline group. Any comparison between two log relative risks must, however, take the variation in each estimate into account (by summing their variances, as described elsewhere ${ }^{55}$ ). Because of the large number of relative risk estimates presented, $99 \%$ CIs are generally used in the figures; however, summary results in the text and figures use $95 \%$ CIs.

To ensure that women in one study were compared directly only with similar women in the same study, all analyses were routinely stratified by study, by centre within study, by fine divisions of age (single years of age from 16 to 69 , then $70-74,75-79,80-84$, and 85-89), parity $(0,1,2,3,4,5,6+$; not known) and hysterectomy status (yes, no, unknown). These stratification variables were selected because they are related both to the use of oral contraceptives and to the risk of developing ovarian cancer. The effect on the main findings of 12 other potential confounding factors (ethnic group, education, age at first birth, family history of breast cancer, age at menarche, menopausal status, use of hormone replacement therapy, height, weight, body-mass index, alcohol use, and smoking) was examined by comparing results before and after stratification for each variable separately and all simultaneously.

When results in the figures are represented by squares and lines the position of the square indicates the value of the relative risk (its area is inversely proportional to the variance of the logarithm of the relative risk, thereby providing an indication of the amount of statistical 
information available for that particular estimate) and the length of the line represents the CI. When appropriate, a trend in the relative risk of ovarian cancer with increasing duration of oral contraceptive use was calculated only among users (ie, relative risks for ever users were compared with each other). For these calculations and for the graphical presentation of such results, the duration of oral contraceptive use associated with a particular category was taken to be the median duration within that category.

To estimate the absolute risk of ovarian cancer associated with 5, 10, and 15 years use of oral contraceptives, the relative risks obtained here were applied to published data for the age-specific incidence and mortality rates for ovarian cancer in high income countries. ${ }^{59,60}$ The age-specific rates were then used to estimate cumulative rates up to age 75 . To illustrate the public-health effect of oral contraceptives on ovarian cancer, the numbers of cancers prevented in each of the five decades, starting with the 1960 s, were estimated by applying the relative risks found here and statistics on oral contraceptive use in different generations of women to age-specific ovarian cancer incidence and mortality rates. In high-income countries the estimated proportions of ever-users of oral contraceptives in each successive 5-year birth cohort from 1916-20 to 1951-55 were: 5\%, 15\%, $29 \%, 40 \%, 51 \%, 65 \%, 76 \%$, and $80 \%$, respectively, with the average years of use among them being $3 \cdot 6,4 \cdot 5,5 \cdot 1$, $5 \cdot 5,5 \cdot 8,6 \cdot 1,6 \cdot 3$, and $6 \cdot 3$, respectively. These estimates were based on the pattern of oral contraceptive use recorded among controls in this collaboration and in a previous international collaboration; ${ }^{55}$ for women born after 1955 use was assumed to be the same as for the 1951-55 birth cohort. In middle-income and low-income countries, oral contraceptive use was uncommon until recently. ${ }^{61,62}$

\section{Role of the funding source}

The sponsors of the study had no role in the study design, data collection, data analysis, data interpretation or writing of the report. The writing committee had full access to all the data and had final responsibility for the decision to submit for publication.

\section{Results}

Details of the 45 participating studies are shown in table 1 . The studies are listed according to their design and, within each type of design, by the median year when the ovarian cancers were diagnosed in each study. Altogether the 45 studies were done in 21 countries, mostly in Europe or the USA, and they contributed a total of 23257 women with ovarian cancer (cases) and 87303 women without ovarian cancer (controls) to the analyses. The cancers were diagnosed in 1993, on average, and the mean age at diagnosis was 56 years; $7 \%$ were aged younger than 35 years, $11 \%$ were aged $35-44$ years, $25 \%$ were aged $45-54$ years, 30\% were aged 55-64 years, and $27 \%$ were older.

\begin{tabular}{|c|c|c|}
\hline $\begin{array}{l}\text { Duration of oral } \\
\text { contraceptive use (mean) }\end{array}$ & Cases/controls & $\mathrm{RR}$ and $99 \% \mathrm{FCl}^{*}$ \\
\hline Never & $14703 / 51908$ & $1.00(0.96-1.04)$ \\
\hline Less than 1 year ( 0.4 years) & $1492 / 6353$ & $1.00(0.91-1.10)$ \\
\hline $1-4$ years $(2 \cdot 4$ years $)$ & $2686 / 11329$ & $0.78(0.73-0.83)$ \\
\hline $5-9$ years $(6 \cdot 8$ years $)$ & $1562 / 7118$ & $0.64(0.59-0.69)$ \\
\hline $10-14$ years ( 11.6 years) & $655 / 3765$ & $0.56(0.50-0.62)$ \\
\hline 15 years or more ( $18 \cdot 3$ years) & $247 / 1639$ & $0.42(0.36-0.49)$ \\
\hline \multicolumn{3}{|c|}{$\begin{array}{l}\text { Numbers do not always add to the total, because of missing values. * Relative } \\
\text { risks (RR) stratified by study, age, parity, and hysterectomy. Test for trend with } \\
\text { duration of use, } p<0.00001 \text {. }\end{array}$} \\
\hline
\end{tabular}

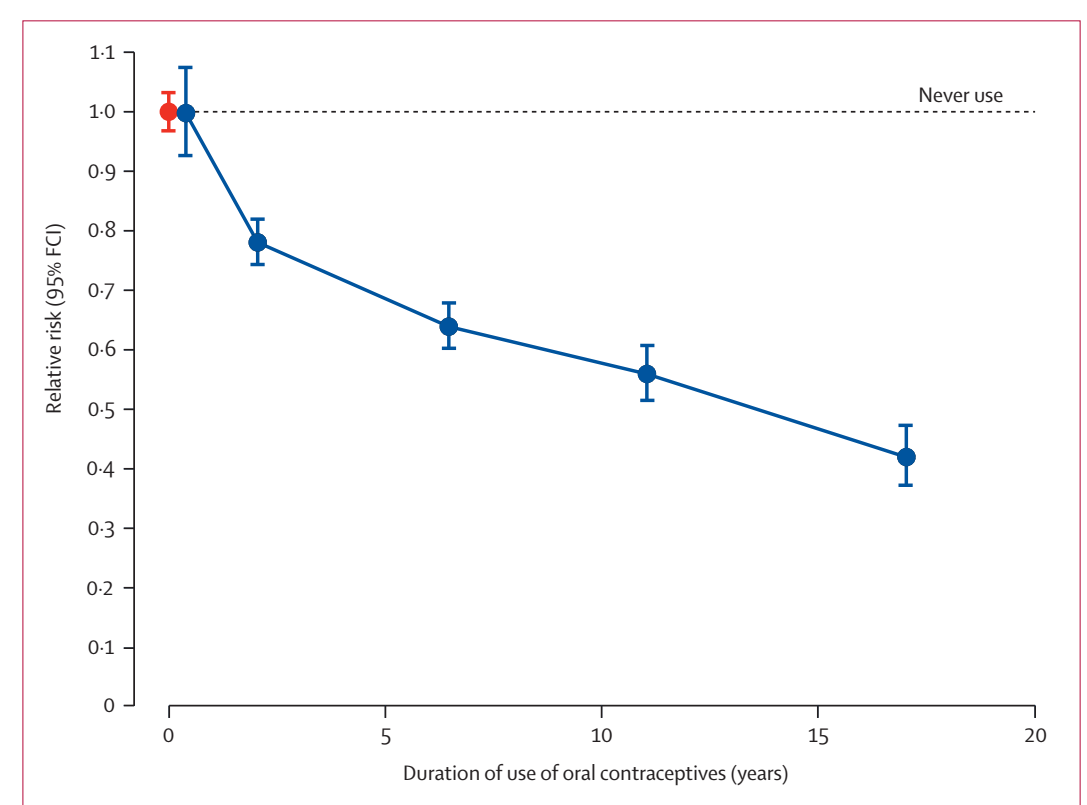

Figure 2: Relative risk ${ }^{*}$ of ovarian cancer by duration of use of oral contraceptives *Stratified by study, age, parity, and hysterectomy.

Overall, 31\% (7308) of the women with ovarian cancer and $37 \%$ (32717) of the controls had used oral contraceptives, and the average duration of use was 4.4 and 5.0 years, respectively. Figure 1 shows the study-specific and combined relative risks of ovarian cancer in ever-users compared with never-users of oral contraceptives. (Studies with information content [var $(\mathrm{O}-\mathrm{E})$ ] less than 20 are included in the "other" category for the relevant study design.) For each of the three types of study design there was a highly significant reduction in the relative risk of ovarian cancer in ever users of oral contraceptives. Overall, for ever vs never users the overall relative risk is $0 \cdot 73,95 \% \mathrm{CI} 0 \cdot 70-0 \cdot 76, \mathrm{p}<0 \cdot 0001$.

The longer that women had used oral contraceptives, the lower their risk of ovarian cancer (table 2). The overall relative risk decreased by $20 \%$ (95\% CI, 18-23\%, $\mathrm{p}<0 \cdot 0001)$ for each 5 years of use (ie, it was multiplied by a factor of 0.8 ). In women who had used oral 


\begin{tabular}{|c|c|c|c|c|c|}
\hline & \multirow[t]{2}{*}{ Ever-users* } & \multicolumn{3}{|c|}{ Duration of use of oral contraceptives } & \multirow{2}{*}{$\begin{array}{l}\text { Percent decline in the risk for } \\
\text { every } 5 \text { years use }(95 \% \mathrm{Cl}) \text {, } \\
\text { comparing ever-users }\end{array}$} \\
\hline & & $<5$ years & $5-9$ years & $10+$ years & \\
\hline \multicolumn{6}{|c|}{ Current use or use less than 10 years previously } \\
\hline Relative risk $(99 \% \mathrm{FCl})$ & $0.57(0.50-0.64) \dagger$ & $0.88(0.75-1.04)$ & $0.52(0.43-0.64)$ & $0.39(0.33-0.47)$ & $28 \cdot 9(23 \cdot 0-34 \cdot 3)$ \\
\hline Cases/controls & $1137 / 8911$ & $636 / 4779$ & $269 / 2268$ & $232 / 1864$ & \\
\hline Mean duration of use & 5.8 years & 1.7 years & $7 \cdot 2$ years & 14.7 years & \\
\hline \multicolumn{6}{|c|}{ Last use $10-19$ years previously } \\
\hline Relative risk ( $99 \% \mathrm{FCl})$ & $0.67(0.62-0.73)$ & $0.85(0.75-0.97)$ & $0.62(0.53-0.73)$ & $0.51(0.44-0.59)$ & $19 \cdot 4(14 \cdot 2-24 \cdot 2)$ \\
\hline Cases/controls & $1626 / 8153$ & $844 / 4559$ & $419 / 1716$ & $363 / 1878$ & \\
\hline Mean duration of use & 5.6 years & 1.6 years & 6.9 years & 13.8 years & \\
\hline \multicolumn{6}{|c|}{ Last use 20-29 years previously } \\
\hline Relative risk ( $99 \% \mathrm{FCl})$ & $0.76(0.71-0.81)$ & $0.81(0.74-0.89)$ & $0.69(0.60-0.78)$ & $0.60(0.51-0.72)$ & $15 \cdot 1(8 \cdot 5-21 \cdot 2)$ \\
\hline Cases/controls & $2202 / 8146$ & $1425 / 4621$ & $528 / 2141$ & $249 / 1384$ & \\
\hline Mean duration of use & 4.6 years & 1.8 years & 6.7 years & 11.8 years & \\
\hline \multicolumn{6}{|c|}{ Last use 30 or more years previously } \\
\hline Relative risk ( $99 \% \mathrm{FCl})$ & $0.86(0.76-0.97)$ & $0.83(0.73-0.95)$ & Insufficient data & Insufficient data & Insufficient data \\
\hline Cases/controls & $697 / 2617$ & $584 / 2161$ & & & \\
\hline Mean duration of use & 2.5 years & $1 \cdot 5$ years & & & \\
\hline \multicolumn{6}{|c|}{$\begin{array}{l}\text { *Never users include } 14703 \text { cases and } 51908 \text { controls with relative risk of } 1.00 \text { ( } 99 \% \text { FCl 0.96-1.04). All relative risks are stratified by study, age, parity, and hysterectomy. } \\
\text { Numbers do not always add to the total, because of missing values. FFor current use and use that ceased less than } 2 \text { years previously, relative risk was } 0.59 \text { ( } 99 \% \text { FCl 0.50-0.70) }\end{array}$} \\
\hline
\end{tabular}

contraceptives for about 15 years the risk of ovarian cancer was halved (figure 2). The effect of various potential confounding factors on the relation shown in figure 2 was examined by adjusting in turn for ethnic

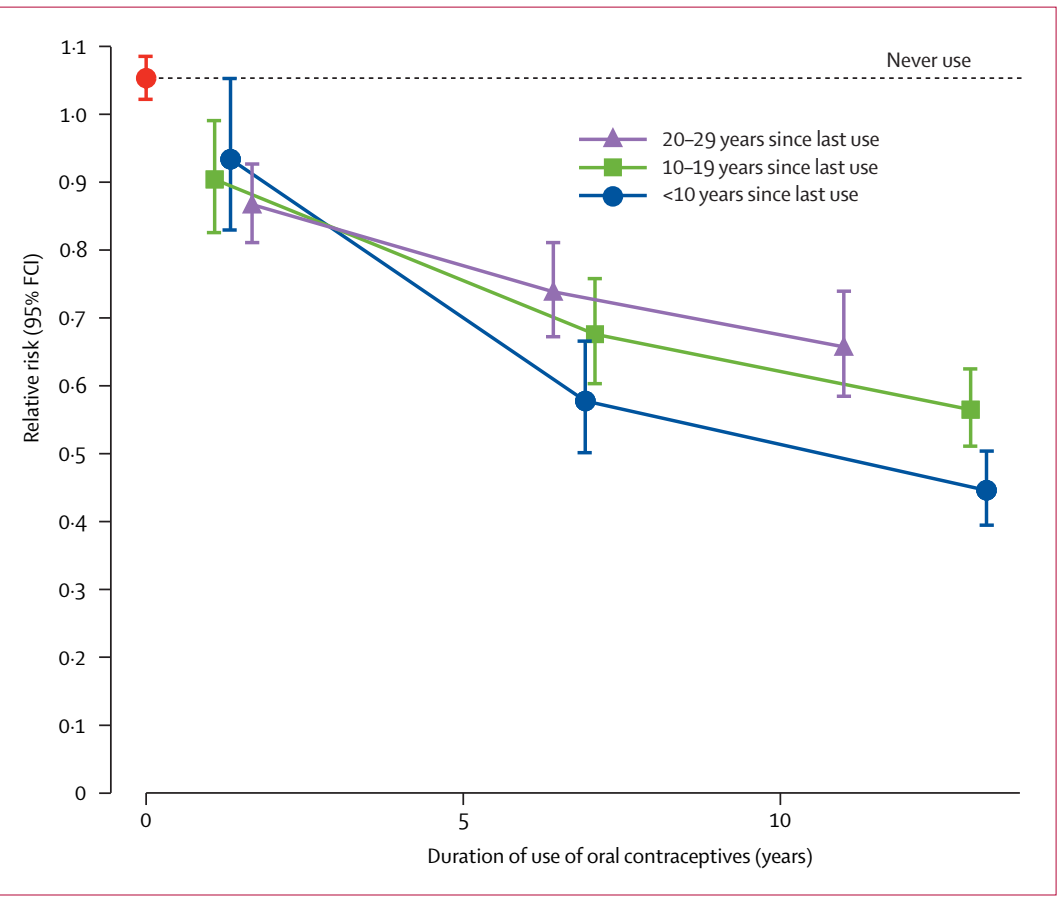

Figure 3: Relative risk* of ovarian cancer by duration and time since last use of oral contraceptives *Stratified by study, age, parity, and hysterectomy. group, education, age at first birth, family history of breast cancer, age at menarche, menopausal status, use of hormone replacement therapy, height, weight, body-mass index, alcohol use, and tobacco consumption and also by adjusting for all the factors simultaneously. All these additional adjustments altered the estimated $20 \%$ decrease in relative risk per 5 years use by less than $1 \%$.

The women with ovarian cancer had stopped use of oral contraceptives an average of 18.6 years previously, and table 3 shows results by time since ceasing use. The relative risks for ovarian cancer were lower the more recently women had used oral contraceptives. The average duration of use was, however, greater in recent users than in those who had stopped a long time previously (table 3 ). When the relation with duration of use was examined within categories of recency of use, there was some wearing off of the effect of oral contraceptives the longer ago use had ceased: the proportional declines in relative risk per 5 years use of oral contraceptives were $29 \%$ for those whose use had ceased less than 10 years previously, 19\% for use ceased 10-19 years previously, and $15 \%$ for use ceased $20-29$ years previously (test for heterogeneity, $\mathrm{p}=0 \cdot 004$, figure 3 ). These findings are unlikely to indicate misclassification of use long ago, since women recall reliably whether or not they took oral contraceptives in the past (but cannot recall the type used)..$^{52}$ Despite this attenuation in proportional (but not in absolute) risk reduction after stopping use, the risk of ovarian cancer was still 


\begin{tabular}{|c|c|c|c|c|c|}
\hline & \multirow[t]{2}{*}{ Ever-users* } & \multicolumn{3}{|c|}{ Duration of use of oral contraceptives } & \multirow{2}{*}{$\begin{array}{l}\text { Percent decline in the risk for } \\
\text { every } 5 \text { years use }(95 \% \mathrm{Cl}) \text {, } \\
\text { comparing ever-users }\end{array}$} \\
\hline & & $<5$ years & $5-9$ years & $10+$ years & \\
\hline \multicolumn{6}{|c|}{ First use before age 20 years } \\
\hline Relative risk $(99 \% \mathrm{FCl})$ & $0.71(0.63-0.81)$ & $0.95(0.80-1.13)$ & $0.65(0.53-0.81)$ & $0.50(0.40-0.64)$ & $24 \cdot 6(17 \cdot 0-31 \cdot 6)$ \\
\hline Cases/controls & 1009/4381 & $509 / 2159$ & 280/1135 & $169 / 841$ & \\
\hline Mean duration of use & 5.4 years & 1.9 years & 7.0 years & $14 \cdot 2$ years & \\
\hline \multicolumn{6}{|c|}{ First use at age $20-24$ years } \\
\hline Relative risk $(99 \% \mathrm{FCl})$ & $0.69(0.64-0.74)$ & $0.81(0.73-0.90)$ & $0.68(0.59-0.78)$ & $0.50(0.43-0.58)$ & $19 \cdot 6(14 \cdot 4-24 \cdot 5)$ \\
\hline Cases/controls & 2051/9384 & $1166 / 5063$ & $508 / 2241$ & $328 / 1824$ & \\
\hline Mean duration of use & $5 \cdot 3$ years & 1.8 years & 6.9 years & 13.9 years & \\
\hline \multicolumn{6}{|c|}{ First use at age $25-29$ years } \\
\hline Relative risk $(99 \% \mathrm{FCl})$ & $0.72(0.66-0.79)$ & $0.84(0.75-0.95)$ & $0.64(0.53-0.78)$ & $0.50(0.41-0.61)$ & $20 \cdot 4(14 \cdot 3-26 \cdot 0)$ \\
\hline Cases/controls & $1310 / 6678$ & $825 / 3881$ & $249 / 1376$ & $183 / 1260$ & \\
\hline Mean duration of use & 4.8 years & 1.6 years & 6.8 years & 13.6 years & \\
\hline \multicolumn{6}{|c|}{ First use at age 30 years or older } \\
\hline Relative risk $(99 \% \mathrm{FCl})$ & $0.75(0.69-0.82)$ & $0.84(0.76-0.93)$ & $0.63(0.53-0.74)$ & $0.56(0.46-0.68)$ & $17 \cdot 6(11 \cdot 6-23 \cdot 2)$ \\
\hline Cases/controls & 1740/9337 & $1131 / 5583$ & 305/1931 & 211/1420 & \\
\hline Mean duration of use & 4.2 years & 1.6 years & 6.8 years & 12.7 years & \\
\hline
\end{tabular}

significantly reduced 30 or more years after use had ceased (table 3 ).

Once duration of use and time since last use of oral contraceptives were taken into account, no other index of the timing of use-eg, women's ages at first and last use, and use before and after the birth of a child-had any material further effect on the relative risk of ovarian cancer. Table 4 shows results according to the women's ages at first use of oral contraceptives. There was no significant heterogeneity in the decline in relative risk with increasing duration of oral contraceptive use across women who started use at different ages (test for heterogeneity, $\mathrm{p}=0 \cdot 5)$. The distribution of women's ages at first use was $16 \%$ for those younger than 20 years, 34\% for $20-24$ years, $21 \%$ for $25-29$ years, $14 \%$ for $30-34$ years, $8 \%$ for $35-39$ years, and $7 \%$ for older ages. Women's ages at last use were closely correlated with their age at first use, and the decline in ovarian cancer risk with increasing duration of use did not differ significantly by women's age at last use (3\% were younger than 20 years at last use, $18 \%$ were $20-24,24 \%$ were $25-29,21 \%$ were $30-34,15 \%$ were $35-39,11 \%$ were $40-44$, and $8 \%$ were older). The decline in ovarian cancer risk with increasing duration of use did not vary significantly by whether women had begun using oral contraceptives before or after the birth of their first child (decreases in relative risk per 5 years of use $26 \%$ vs $18 \%$; test for heterogeneity, $\mathrm{p}=0 \cdot 1$ ).

As described in the methods section, the oestrogen dose in oral contraceptive preparations typically used in

\begin{tabular}{|c|c|c|c|c|}
\hline & \multicolumn{3}{|c|}{ Mid-year of use of oral contraceptives* } & \multirow{2}{*}{$\begin{array}{l}\text { Test for heterogeneity } \\
\text { by year of use ( } p \text { value), } \\
\text { comparing ever-users }\end{array}$} \\
\hline & $\begin{array}{l}\text { 1960s (mostly } \\
\text { high dose) }\end{array}$ & $\begin{array}{l}1970 \text { (mostly } \\
\text { medium dose) }\end{array}$ & $\begin{array}{l}1980 \text { (mostly } \\
\text { low dose) }\end{array}$ & \\
\hline \multicolumn{5}{|c|}{ Current use or use that ceased less than 10 years previously } \\
\hline Relative risk (99\% FCI) & $0.52(0.36-0.75)$ & $0.59(0.51-0.70)$ & $0.55(0.46-0.65)$ & 0.6 \\
\hline Cases/controls & $77 / 588$ & $474 / 5164$ & $582 / 3131$ & \\
\hline Mean duration of use & $7 \cdot 4$ years & $5 \cdot 7$ years & 5.7 years & \\
\hline \multicolumn{5}{|c|}{ Last use $10-19$ years previously } \\
\hline Relative risk ( $99 \% \mathrm{FCl})$ & $0.70(0.59-0.83)$ & $0.65(0.59-0.72)$ & $0.70(0.53-0.93)$ & 0.6 \\
\hline Cases/controls & $387 / 3027$ & $1077 / 4609$ & $156 / 499$ & \\
\hline Mean duration of use & 3.5 years & 6.9 years & 4.8 years & \\
\hline \multicolumn{5}{|c|}{ Last use $20-29$ years previously } \\
\hline Relative risk ( $99 \% \mathrm{FCl})$ & $0.78(0 \cdot 70-0.88)$ & $0.73(0.67-0.81)$ & Insufficient data & 0.5 \\
\hline Cases/controls & $1037 / 3530$ & $1152 / 4567$ & & \\
\hline Mean duration of use & 3.7 years & 5.4 years & & \\
\hline \multicolumn{5}{|c|}{ Last use 30 or more years previously } \\
\hline Relative risk $(99 \% \mathrm{FCl})$ & $0.88(0 \cdot 77-1.00)$ & $0.79(0.57-1.11)$ & No data & 0.5 \\
\hline Cases/controls & $620 / 2245$ & $75 / 342$ & & \\
\hline Mean duration of use & 2.5 years & $2 \cdot 1$ years & & \\
\hline $\begin{array}{l}\text { *Never users include } 1470 \\
\text { are stratified by study, age }\end{array}$ & $\begin{array}{l}3 \text { cases and } 51908 \mathrm{cc} \\
\text {, parity, and hysterec }\end{array}$ & $\begin{array}{l}\text { nntrols with relative ri } \\
\text { omy. }\end{array}$ & sk of $1.00(99 \% \mathrm{FCl}, 0$ & .96-1.04). All relative risks \\
\hline
\end{tabular}

the 1960 s was more than double that of preparations typically used in the $1980 \mathrm{~s} .^{29,53,54}$ Among women with ovarian cancer, almost $40 \%$ had a mid-year of oral 


\begin{tabular}{|c|c|c|c|c|}
\hline & Cases/controls* & $\begin{array}{l}\text { Users only: percent reduction } \\
\text { in risk' per } 5 \text { years of oral } \\
\text { contraceptive use (SE) }\end{array}$ & $\begin{array}{l}\text { Users only: percent } r \\
\text { in risk† per } 5 \text { years } \\
\text { contraceptive use an }\end{array}$ & $\begin{array}{l}\text { eduction } \\
\text { of oral } \\
d 99 \% \mathrm{Cl}\end{array}$ \\
\hline All women & $21345 / 82112$ & $20 \cdot 3(1 \cdot 8)$ & & \\
\hline \multicolumn{5}{|l|}{ Parity } \\
\hline 0 & $4374 / 12445$ & $25 \cdot 3(4 \cdot 7)$ & & \\
\hline $\begin{array}{l}1 \\
2\end{array}$ & $\begin{array}{l}3260 / 10691 \\
647 / 23005\end{array}$ & $\begin{array}{l}24.8(4.9) \\
18.0(2.9)\end{array}$ & & \\
\hline 3 & $3846 / 16017$ & $\begin{array}{l}18.0(2.9) \\
20.3(3.9)\end{array}$ & & \\
\hline$\geq 4$ & $3179 / 18995$ & $17 \cdot 3(4 \cdot 7)$ & & \\
\hline \multicolumn{5}{|l|}{ Age at first birth } \\
\hline $\begin{array}{l}<20 \\
20-24\end{array}$ & $\begin{array}{l}2123 / 12236 \\
7169 / 29817\end{array}$ & $\begin{array}{l}14.9(6.0) \\
21 \cdot 3(3.0)\end{array}$ & & \\
\hline $25-29$ & $4970 / 18346$ & $14 \cdot 1(4.0)$ & & \\
\hline$\geq 30$ & 2038/7419 & $22 \cdot 2(7 \cdot 2)$ & & \\
\hline \multicolumn{5}{|l|}{ Age at diagnosis } \\
\hline$\geq 50$ & $\begin{array}{c}5902 / 29961 \\
15443 / 52151\end{array}$ & $\begin{array}{l}28.2(3.4) \\
17 \cdot 3(2 \cdot 1)\end{array}$ & & \\
\hline \multicolumn{5}{|l|}{ Ethnic origin } \\
\hline $\begin{array}{l}\text { White } \\
\text { Other }\end{array}$ & $12782 / 43499$ & $23 \cdot 4(2.6)$ & & \\
\hline \multicolumn{5}{|l|}{ Education } \\
\hline$<13$ years & $13301 / 55542$ & $17 \cdot 3(2 \cdot 4)$ & & \\
\hline$\geq 13$ years & $5579 / 20360$ & $21 \cdot 6(3 \cdot 4)$ & & \\
\hline \multicolumn{5}{|c|}{ Mother or sister with breast cancer } \\
\hline $\begin{array}{l}\text { Yes } \\
\text { No }\end{array}$ & $1793 / 4583$ & $19 \cdot 0(7.4)$ & & \\
\hline \multicolumn{5}{|l|}{ Age at menarche } \\
\hline$<13$ & $8008 / 27013$ & $20.9(3.1)$ & & \\
\hline & $12770 / 52931$ & $20 \cdot 3(2.4)$ & & \\
\hline \multicolumn{5}{|l|}{ Menopausal status } \\
\hline Premenopausal & $5899 / 30933$ & $27.0(3 \cdot 2)$ & & \\
\hline Postmenopausal & $13915 / 45368$ & $16.6(2.5)$ & & \\
\hline \multicolumn{5}{|c|}{ Hormone replacement therapy } \\
\hline Ever & $4122 / 13869$ & $16 \cdot 5(4 \cdot 0)$ & & \\
\hline Never & $7635 / 25229$ & $20 \cdot 3(4 \cdot 1)$ & & \\
\hline \multicolumn{5}{|l|}{ Hysterectomy } \\
\hline $\begin{array}{l}\text { Yes } \\
\text { No }\end{array}$ & $\begin{array}{r}2996 / 10008 \\
16818 / 68580\end{array}$ & $\begin{array}{l}12 \cdot 8(5 \cdot 2) \\
21 \cdot 1(1.9)\end{array}$ & & \\
\hline \multicolumn{5}{|l|}{ Height } \\
\hline $\begin{array}{l}<165 \mathrm{~cm} \\
\geq 165 \mathrm{~cm}\end{array}$ & $\begin{array}{c}10931 / 31928 \\
7586 / 22646\end{array}$ & $\begin{array}{l}18 \cdot 6(2 \cdot 7) \\
19 \cdot 3(3.0)\end{array}$ & & \\
\hline \multicolumn{5}{|l|}{ Weight } \\
\hline $\begin{array}{l}<65 \mathrm{~kg} \\
\geq 65 \mathrm{~kg}\end{array}$ & $\begin{array}{r}9433 / 27078 \\
8988 / 27057\end{array}$ & $\begin{array}{l}19 \cdot 3(2 \cdot 8) \\
18.5(2.9)\end{array}$ & & \\
\hline \multicolumn{5}{|l|}{ Body-mass index } \\
\hline$<25 \mathrm{~kg} / \mathrm{m}^{2}$ & $10869 / 33251$ & $19 \cdot 7(2.5)$ & & \\
\hline$\geq 25 \mathrm{~kg} / \mathrm{m}^{2}$ & $8638 / 26985$ & $21 \cdot 2(3 \cdot 0)$ & & \\
\hline \multicolumn{5}{|l|}{ Alcohol use } \\
\hline$<50 \mathrm{gm}$ per week & $9925 / 48497$ & $17.0(2.5)$ & & \\
\hline \multirow{2}{*}{\multicolumn{5}{|c|}{ Tobacco use }} \\
\hline & & & & \\
\hline \multirow{2}{*}{$\begin{array}{l}\text { Ever } \\
\text { Never }\end{array}$} & $10688 / 37561$ & $16.9(2 \cdot 9)$ & & \\
\hline & & 40 & $10 \%$ & $0 \%$ \\
\hline
\end{tabular}

Figure 4: Percent reduction in ovarian cancer risk per 5 years oral contraceptive use for various subgroups Dotted line represents overall result for all women. *Women with missing values are not included for each variable. †Stratified by study, age, parity, and hysterectomy.

contraceptive use in the 1960 s and $13 \%$ had a mid-year of use in the 1980 s or later (table 5). Those with a mid-year of use in the 1960s had, as expected, ceased use much longer ago than those with a mid-year of use in the 1980s or later ( 25 years vs 5 years previously). For a given time since last use, however, calendar year of use had little effect on the relative risk of ovarian cancer (table 5). Sensitivity analyses were done classifying women according to the calendar year of first use and calendar year of last use but, again, no obvious differences in ovarian cancer risk were found.

The magnitude of the decline in the relative risk of ovarian cancer with duration of use did not vary significantly according to 13 of the 15 personal characteristics examined (figure 4). Significant variation was seen only with age at diagnosis and menopausal status. However, the younger and pre-menopausal women had ceased use of oral contraceptives more recently than the older and postmenopausal women. When analyses were restricted to women whose use ceased 10-29 years previously (the only group with broadly similar recency of use and also with sufficient information to compare younger versus older women and pre-menopausal versus post-menopausal women), there was no significant heterogeneity by either age $(p=0 \cdot 1)$ or menopausal status $(p=0 \cdot 4)$. There was some variation in the magnitude of the decline in relative risk of ovarian cancer for each year of use of oral contraceptives across studies $\left(\chi_{27}^{2}=49 \cdot 1, \quad \mathrm{p}=0 \cdot 006\right.$; figure 1) and by study design $\left(\chi^{2}{ }_{2}=10 \cdot 4, p=0 \cdot 006\right)$. This heterogeneity again reflects the variation in age and thus time since last use of oral contraceptives: cases in the prospective compared with the case-control studies were older (mean ages of 64 vs 52 years at diagnosis) and had ceased use longer ago (means of 24 vs 15 years since last use).

Data for histological subtype was available for 17099 women with ovarian cancer (74\% of the total). Among these women the risk of ovarian cancer decreased by $21 \%$ for each 5 years of use of oral contraceptives (figure 5), similar to the $20 \%$ seen for all women (figure 1 ). The reductions in risk per 5 years of oral contraceptive use were broadly similar for epithelial and non-epithelial tumours. Among the epithelial tumours there was, however, heterogeneity across histological types (test for heterogeneity, $p=0 \cdot 0007)$ mainly because oral contraceptives seem to have little effect on mucinous tumours (12\% of the total with histology). There was no significant heterogeneity in the trends with duration of use between the non-mucinous epithelial tumours $(p=0 \cdot 5)$. The findings were similar when the mucinous and serous tumours were subdivided into whether they were of only borderline malignancy or were fully malignant (figure 5).

Figure 6 shows, for women in high income countries, the estimated cumulative incidence and mortality from ovarian cancer for never users of oral contraceptives and for those who used them for 5, 10, and 15 years, respectively, beginning at age 20 years. The percent decline in ovarian cancer rates for every 5 years of use was assumed to be $29 \%$ in current users and those who ceased use in the previous 10 years, 19\% in those who ceased use 10-19 years previously, and 15\% in those who ceased use 20 or more years previously. For women who never used oral contraceptives an estimated $1 \cdot 2$ in every 100 are diagnosed with ovarian cancer and 0.7 in every 100 die from the disease before the age of 75 years (in the absence of other causes of death). For 10 years use of oral contraceptives the estimated cumulative incidence was 0.8 per 100 and mortality was 0.5 per 100 . 
As the reduction in risk is roughly proportional to duration of use, this means that for every 5000 woman-years of oral contraceptive use about two ovarian cancers and one death from the disease are prevented. (Ovarian cancers arising after age 75 years are not included in these or in subsequent calculations, nor are deaths from ovarian cancer after age 75 years that arose earlier.)

For women with background rates of ovarian cancer greater than the average, such as those with a family history of breast cancer or who are nulliparous, the reduction in absolute risk would be greater still. Conversely, for women with lower than average background rates the reduction in absolute risk would be less. For example, ovarian cancer rates in many middle-income and low-income countries are about half those in high income countries, ${ }^{59,60}$ and so about two ovarian cancers and one death from the disease would be prevented for every 10000 woman-years of oral contraceptive use.

\section{Discussion}

This worldwide collaboration has brought together and re-analysed data for over 23000 women with ovarian cancer and 87000 women without ovarian cancer from 21 countries. The results confirm that women who use oral contraceptives are at a reduced risk of ovarian cancer and show that substantial protection continues for decades. The reduction in risk is greater the longer that women used oral contraceptives and, although the relative (but not the absolute) risks are somewhat attenuated over time, there is still a significant reduction in risk more than 30 years after use has ceased. The relative decline in ovarian cancer risk with increasing duration of use does not vary substantially by women's ethnicity, education, age at menarche, parity, family history of breast cancer, use of hormone replacement therapy, body-mass index, height, or their consumption of alcohol and tobacco. The incidence of mucinous tumours (12\% of the total) was little affected by oral contraceptives, but otherwise the proportional risk reduction did not vary much between different histological types.

This collaboration includes individual data from 45 epidemiological studies, most of the eligible studies worldwide that have collected information on oral contraceptive use and ovarian cancer. Despite extensive efforts to identify studies with unpublished results, we cannot guarantee that none has been overlooked or that information from continuing prospective studies is up to date, since such studies are accumulating data beyond the time when they contributed to this collaboration. Three published studies ${ }^{48-50}$ could not contribute their data, and only some of the EPIC study centres ${ }^{25,30,36}$ have done so. Nevertheless, these studies would have increased the number of cases by only about another 3\%, and the published results from the studies not included ${ }^{48-50}$ do not

\begin{tabular}{|c|c|c|c|c|}
\hline & Cases & $\begin{array}{l}\text { Users only: percent reduction } \\
\text { in risk* per } 5 \text { years of oral } \\
\text { contraceptive use (SE) }\end{array}$ & $\begin{array}{l}\text { Users only: percent reduct } \\
\text { in risk* per } 5 \text { years of or } \\
\text { contraceptive use and } 99\end{array}$ & $\begin{array}{l}\text { tion } \\
\text { ral } \\
\% \mathrm{Cl}\end{array}$ \\
\hline All with recorded histology & 17099 & $20 \cdot 5(1 \cdot 9)$ & & \\
\hline \multicolumn{5}{|l|}{ Epithelial } \\
\hline Clear cell & 740 & $21 \cdot 3(7 \cdot 3)$ & & \\
\hline Endometrioid & 1994 & $27 \cdot 1(4 \cdot 8)$ & & \\
\hline Mucinous & 2027 & $4 \cdot 0(4 \cdot 7)$ & - & \\
\hline Mucinous malignant & 1412 & $6 \cdot 7(5 \cdot 8)$ & $\square$ & - \\
\hline Mucinous borderline & 615 & $-1 \cdot 5(7 \cdot 7)$ & & $\longrightarrow$ \\
\hline Serous & 7131 & $20 \cdot 9(2 \cdot 7)$ & & \\
\hline Serous malignant & 6263 & $22 \cdot 1(2 \cdot 9)$ & & \\
\hline Serous borderline & 868 & $13 \cdot 0(6 \cdot 8)$ & $\square-$ & - \\
\hline Other/mixed & 3436 & $20 \cdot 8(3 \cdot 9)$ & & \\
\hline Non-epithelial & 589 & $19 \cdot 7(10 \cdot 8)$ & & - \\
\hline \multirow{2}{*}{$\begin{array}{l}\text { Malignant tumour } \\
\text { not otherwise specified }\end{array}$} & 1182 & $25 \cdot 8(7 \cdot 8)$ & & \\
\hline & & & $\% \quad 30 \%$ & $-10 \%$ \\
\hline
\end{tabular}

Figure 5: Percent reduction in risk per 5 years use, by ovarian tumour histology

Dotted line represents overall result for all women with recorded histology. Tumour subcategories are shown as open squares; the 23 endometroid tumours of borderline malignancy are too few to examine separately. *Stratified by study, age, parity, and hysterectomy.

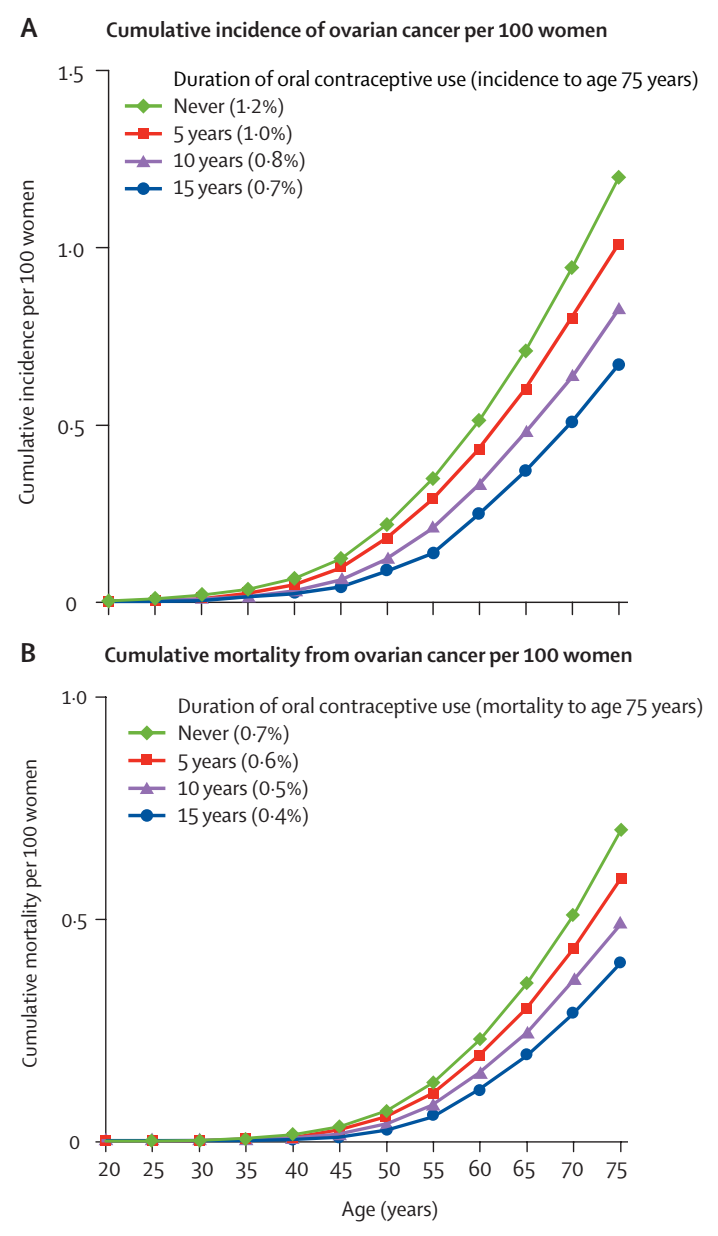

Figure 6: Absolute risk of ovarian cancer for women in high income countries, by duration of use of oral contraceptives

(A) Cumulative incidence of ovarian cancer per 100 women. (B) Cumulative mortality from ovarian cancer per 100 women. 


\begin{tabular}{|lll|}
\hline & High-income countries & $\begin{array}{l}\text { Low-income and middle-income } \\
\text { countries* }\end{array}$ \\
\hline $1960 \mathrm{~s}$ & $<1 \%$ &.. \\
$1970 \mathrm{~s}$ & $1 \%$ &.. \\
$1980 \mathrm{~s}$ & $5 \%$ &.. \\
$1990 \mathrm{~s}$ & $9 \%$ & $<1 \%$ \\
$2000 \mathrm{~s}$ & $13 \%$ & $1 \%$ \\
*Includes former Socialist economies. ${ }^{59,61}$ & \\
\hline $\begin{array}{l}\text { Table 6: Estimated proportion of ovarian cancers prevented before } \\
\text { age 75 years by past patterns of use of oral contraceptives in different } \\
\text { countries over five decades }\end{array}$ \\
\hline
\end{tabular}

differ from those reported. Thus, failure to include all the available data has not materially altered the overall findings.

Substantial reductions in the oestrogen content of oral contraceptives have occurred over the 50 or so years that oral contraceptives have been in use. The ovarian cancers in this study were diagnosed, on average, almost 20 years after the women had last used oral contraceptives and, because the specific oral contraceptive preparations used are unreliably reported many years after use ceases ${ }^{52}$ calendar year is used here as an indicator of the average oestrogen dose of the preparations. Typical oestrogen doses in the 1960s were more than double the typical doses in the 1980s and later, ${ }^{29,53,54}$ but for a given pattern of usage there was no apparent variation in the relative risk of ovarian cancer between women whose oral contraceptive use was during the 1960s, 1970s, and 1980s (table 5), suggesting no appreciable differential effect of preparations typically used over the decades.

One of the main effects of oral contraceptives is to suppress ovarian activity, so some protection against neoplastic change is plausible. This makes it reasonable to infer that the associations seen here are chiefly causal-ie, that previous oral contraceptive use decreases the age-specific incidence of ovarian cancer in otherwise similar women. The exact mechanism by which oral contraceptives cause such a profound and long-lasting protection against ovarian cancer is, nevertheless, not well understood.

Oral contraceptives were first licensed almost 50 years ago. In the 1960s and 1970s most women who had used oral contraceptives were younger than 50 and so relatively few ovarian cancers would have been prevented (table 6). In subsequent decades the estimated proportion of cancers prevented increased, in part due to the increasing number of ever-users and in part due to the increasing age of past users, such that in the 2000s an estimated $13 \%$ of ovarian cancers before age 75 years were being prevented in women in high-income countries. In middleincome and low-income countries oral contraceptives have probably had little effect so far on ovarian cancer incidence, since use was uncommon until the 1980s. ${ }^{61,62}$
To illustrate the public-health implications of relative risks such as those reported here and the pattern of oral contraceptive use around the world, these results suggest that of the order of 200000 incident cases and 100000 deaths from ovarian cancer have already been prevented over the last 50 years. The number of cancers prevented each year is likely to increase substantially in the future, with the further ageing of past users of oral contraceptives and the increasing numbers of new users, especially in middle-income and low-income countries. In 2002 an estimated 80 million of a total of 120 million oral contraceptives users worldwide were in middle-income and low-income countries. ${ }^{61}$ With this number of oral contraceptive users and current ovarian cancer incidence rates, the number of ovarian cancers prevented would rise over the next few decades to about 30000 every year. However, the number prevented is likely to be still greater since the prevalence of oral contraceptive use in middle-income and low-income countries is predicted to increase. ${ }^{62}$

\section{Contributors}

Writing committee: V Beral, R Doll*, C Hermon, R Peto, G Reeves. Steering committee: L Brinton, A C Green, P Marchbanks, E Negri, R Ness, P Peeters, M Vessey.

Collaborators (in alphabetical order of institution, study name, or location): American Cancer Society, Atlanta, USA: E E Calle, C Rodriguez; Aviano Cancer Center, Pordenone, Italy: L Dal Maso, R Talamini; Brigham and Women's Hospital and Harvard Medical School, USA: D Cramer and Channing Laboratory: S E Hankinson, S S Tworoger for the Nurses' Health Study; Cancer and Radiation Epidemiology Unit, the Gertner Institute, Israel: A Chetrit, G Hirsh-Yechezkel, F Lubin, S Sadetzki; Cancer Epidemiology Unit, Oxford, UK (Secretariat): P Appleby, E Banks, V Beral, A Berrington de Gonzalez, D Bull, B Crossley, A Goodill, I Green, J Green, C Hermon, T Key, G Reeves; Cancer Research UK/MRC/BHF Clinical Trial Service Unit \& Epidemiological Studies Unit (CTSU), Oxford, UK: R Collins, R Doll*, R Peto; Catalan Institute of Oncology, Barcelona, Spain: C A Gonzalez; Centers for Disease Control \& Prevention, GA, USA: N Lee, P Marchbanks, H W Ory, H B Peterson, P A Wingo; Chiang Mai University, Chiang Mai, Thailand: N Martin, T Pardthaisong, S Silpisornkosol, C Theetranont; Chulalongkorn University, Bangkok, Thailand: B Boosiri, S Chutivongse, P Jimakorn, P Virutamasen,

C Wongsrichanalai; Dartmouth Medical School, New Hampshire, USA: L Titus-Ernstoff; Department of Gynaecology and Obstetrics, Herlev University Hospital, Denmark: B J Mosgaard; Department of Public Health, Oxford, UK: M Vessey, D Yeates; Deutsches Krebsforschungszentrum, Heidelberg, Germany: J Chang-Claude; Fred Hutchinson Cancer Research Center, University of Washington, Seattle, USA: M A Rossing, D Thomas, N Weiss; International Agency for Research in Cancer, Lyon, France: S Franceschi; Istituto "Mario Negri”, University of Milan, Italy: C La Vecchia, E Negri; Karolinska Institutet, Stockholm, Sweden: H O Adami, C Magnusson, T Riman, E Weiderpass; A Wolk; National Cancer Institute, MD, USA: L A Brinton, D M Freedman, P Hartge, J M Lacey, R Hoover; Maastricht University, Netherlands: L J Schouten, P A van den Brandt; Mahidol University, Bangkok, Thailand: N Chantarakul, S Koetsawang, D Rachawat; Norwegian Institute of Public Health, Oslo, Norway: S Graff-Iversen, R Selmer; Queensland Institute of Medical Research and University of Queensland: C J Bain, A C Green, D M Purdie, V Siskind, P M Webb; Roswell Park Cancer Institute, New York, USA: S E McCann; Royal College of General Practitioners Oral Contraception Study, UK: P Hannaford, C Kay; School of Public Health, Curtin University of Technology, Perth, Australia: C W Binns, A H Lee, M Zhang; School of Public Health and Health Sciences, University of Massachusetts, USA: P Nasca; Slone Epidemiology Center, Boston University, USA: P F Coogan, L Rosenberg; Stanford University, 
Stanford, USA: J Kelsey, R Paffenbarger*; A Whittemore; University of Athens Medical School, Athens, Greece: K Katsouyanni,

A Trichopoulou, D Trichopoulos, A Tzonou; University of Chile, Santiago, Chile: A Dabancens, L Martinez, R Molina, O Salas; University of Hawaii, USA: M T Goodman, G Laurie, M E Carney, L R Wilkens; University Hospital, Lund, Sweden: A Bladstrom, H Olsson; University of Pittsburgh, Pittsburgh, USA: R B Ness; University of Pennsylvania, Philadelphia, USA: J A Grisso, M Morgan, J E Wheeler; University Medical Centre Utrecht, Netherlands: P Peeters University of Southern California, LA, USA: J Casagrande, M C Pike, RK Ross*, AH Wu; University of Tromso, Tromso, Norway: M Kumle, E Lund, Washington DC, USA: L McGowan; Vanderbilt University, TN, USA: X O Shu, W Zheng; World Health Organisation, UNDP/UNFPA/WHO/World Bank Special Programme of Research, Development and Research Training in Human Reproduction, Geneva, Switzerland: T M M Farley, S Holck, O Meirik; Yale School of Public Health, USA: H A Risch.

*Deceased.

\section{Conflict of interest statement}

The writing committee declare no conflict of interest.

\section{Acknowledgments}

Central pooling, checking, and analysis of data was supported by Cancer Research UK and the Medical Research Council.

\section{References}

1 Newhouse ML, Pearson RM, Fullerton JM, Boesen EAM, Shannon HS. A case-control study of carcinoma of the ovary. $\mathrm{Br} J$ Preventive Social Medicine 1977; 31: 148-53.

2 Casagrande JT, Pike M, Ross R, Louie E, Roy S, Henderson BE. 'Incessant ovulation' and ovarian cancer. Lancet 1979; 2: 170-73.

3 McGowan L, Parent L, Lednar W, Norris HJ. The woman at risk for developing ovarian cancer. Gynecol Oncol 1979; 7: 325-44.

4 Hildreth NG, Kelsey JL, LiVolsi VA, et al. An epidemiologic study of epithelial carcinoma of the ovary. Am J Epidemiol 1981; 114: 398-405.

5 Weiss NS, Lyon JL, Liff JM, Vollmer WM, Daling JR. Incidence of ovarian cancer in relation to the use of oral contraceptives. Int J Cancer 1981; 28: 669-71.

6 Cramer DW, Hutchison GB, Welch WR, Scully RE, Ryan KJ. Determinants of ovarian cancer risk. I. Reproductive experiences and family history. J Natl Cancer Inst 1983; 71: 711-16.

7 Nasca PC, Greenwald P, Chorost S, Richart R, Caputo T. An epidemiologic case-control study of ovarian cancer and reproductive factors. Am J Epidemiol 1984; 119: 705-13.

8 The Cancer Steroid Hormone Study of the Centers for Disease Control and the National Institute of Child Health and Human Development. The reduction in risk of ovarian cancer associated with oral contraceptive use. N Engl J Med 1987; 316: 650-55.

9 Wu ML, Whittemore AS, Paffenbarger RS, et al. Personal and environmental characteristics related to epithelial ovarian cancer. I. Reproductive and menstrual evens and oral contraceptive use. Am J Epidemiol 1988; 128: 1216-27.

10 Whittemore A, Wu M, Paffenbarger R, et al. Personal and environmental characteristics related to epithelial ovarian cancer. II Exposures to talcum powder, tobacco, alcohol and coffee. Am J Epidemiol 1988; 128: 1228-40.

11 Booth M, Beral V, Smith P. Risk factors for ovarian cancer: a case-control study. Br J Cancer 1989; 60: 592-98.

12 Hartge P, Schiffman MH, Hoover R, McGowan L, Lesher L, Norris HJ. A case-control study of epithelial ovarian cancer. Am J Obstet Gynecol 1989; 161: 10-16.

13 Shu XO, Brinton LA, Gao YT, Yuan JM. Population-based case-control study of ovarian cancer in Shanghai. Cancer Res 1989; 49: 3670-74.

14 WHO Collaborative Study of Neoplasia and Steroid Contraceptives. Epithelial ovarian cancer and combined oral contraceptives. Int J Epidemiol 1989; 18: 538-45.

15 Parazzini F, La Vecchia C, Negri E, Bocciolone L, Fedele L, Franceschi S. Oral contraceptive use and the risk of ovarian cancer: an Italian case-control study. Eur J Cancer 1991; 27: 594-98.

16 Polychronopoulou A, Tzonou A, Hsieh CC, et al. Reproductive variables, tobacco, ethanol, coffee and somatometry as risk factors for ovarian cancer. Int J Cancer 1993; 55: 402-07.
17 Risch HA, Marrett LD, Howe GR. Parity, contraception, infertility and the risk of epithelial ovarian cancer. Am J Epidemiol 1994; 140: 585-97.

18 Rosenberg L, Palmer JR, Zauber Ag, et al. A case-control study of oral contraceptive use and invasive epithelial ovarian cancer. Am J Epidemiol 1994; 139: 654-61.

19 Hankinson SE, Colditz GA, Hunter DJ, et al. A prospective study of reproductive factors and risk of epithelial ovarian cancer. Cancer 1995; 76: 284-90

20 Purdie D, Green A, Bain C, et al, for the Survey of Women's Health Study Group. Reproductive and other factors and risk of epithelial ovarian cancer: an Australian case-control study. Int J Cancer 1995; 62: 678-84.

21 Rodriguez C, Calle EE, Coates RJ, Miracle McMahill HL, Thun MJ, Health CW. Estrogen replacement therapy and fatal ovarian cancer. Am J Epidemiol 1995; 141: 828-35.

22 Vessey M, Painter R. Endometrial and ovarian cancer and oral contraceptives-findings in a large cohort study. Br J Cancer 1995; 71: $1340-42$.

23 McCann SE, Moysich KB, Mettlin C. Intakes of selected nutrients and food groups and risk of ovarian cancer. Nutr Cancer 2001; 39: $19-28$.

24 Mosgaard BJ, Lidegaard O, Kjaer S, Schou G, Andersen A. Infertility, fertility drugs, and invasive ovarian cancer: a case-control study. Fertil Steril 1997; 67: 1005-12.

25 Agudo A, Amiano P, Barcos A, et al. Dietary intake of vegetables and fruit among adults in 5 regions of Spain. EPIC Group of Spain Prospective Investigation into Cancer and Nutrition. Eur J Clin Nutr 1999; 53: 174-80

26 Beral V, Hermon C, Key T, Hannaford P, Darby S, Reeves G. Mortality associated with oral contraceptive use: 25 year follow-up of cohort of 46000 women from Royal College of General Practitioners' Oral Contraception Study. BMJ 1999; 318: 96-100.

27 Million Women Study Collaborative Group. The Million Women Study: design and characteristics of the study population. Breast Cancer Research 1999; 1: 73-80.

28 Cramer DW, Greenberg R, Titus-Ernstoff L, et al. A case-control study of galactose consumption and metabolism in relation to ovarian cancer. Cancer Epidemiol Biomarkers Prev 2000; 9: 95-101.

29 Ness RB, Grisso JA, Klapper J, et al, and the SHARE Study Group. Risk of ovarian cancer in relation to estrogen and progestin dose and use characteristics of oral contraceptives. Am J Epidemiol 2000; 152: 233-41.

30 Boker LK, van Noord PA, van der Schouw YT, et al. Prospect-EPIC Utrecht: study design and characteristics of the cohort population. Eur J Epidemiol 2001; 17: 1047-53.

31 Chiaffarino F, Pelucchi C, Parazzini F, et al. Reproductive and hormonal factors and ovarian cancer. Ann Oncology 2001; 12: $337-41$.

32 Modan B, Hartge P, Hirsh-Yechezkel G, et al, for the National Israe Ovarian Cancer Study. Parity, oral contraceptives, and the risk of ovarian cancer among carriers and noncarriers of a BRCA1 or BRCA2 mutation. N Engl J Med 2001; 345: 235-40.

33 Goodman MT, Wu AH, Tung K-H et al Association of dairy products, lactose and calcium with the risk of ovarian cancer. Am J Epidemiol 2002; 156: 148-57.

34 Riman T, Dickman PW, Nilsson S, et al. Risk factors for invasive epithelial ovarian cancer: results from a Swedish case-control study. Am J Epidemiol 2002; 156: 363-73.

35 Royar J, Becher H, Chang-Claude J. Low dose oral contraceptives: protective effect on ovarian cancer risk. Int J Cancer 2002; 95: $370-74$.

36 Davey GK, Spencer EA, Appleby PN, Allen NE, Knox KH, Key TJ. EPIC-Oxford: lifestyle characteristics and nutrient intakes in a cohort of 33883 meat-eaters and 31546 non meat-eaters in the UK. Public Health Nutr 2003; 6: 259-69.

37 McCann SE, Freudenheim JL, Marshall JR, Graham S. Risk of human ovarian cancer is related to dietary intake of selected nutrients, phytochemicals and food groups. J Nutr 2003; 133: $1937-42$

38 Olsson HL, Ingvar C, Bladstrom A. Hormone replacement therapy containing progestins and given continuously increases breast carcinoma risk in Sweden. Cancer 2003; 97: 1387-92. 
39 Bakken K, Alsaker E, Eggen AE, Lund E. Hormone replacement therapy and incidence of hormone-dependent cancers in the Norwegian women and cancer study. Int J Cancer 2004; 112: $130-34$.

40 Hannan LM, Leitzmann MF, Lacey JV, et al. Physical activity and risk of ovarian cancer: a prospective cohort study in the United States. Cancer Epidemiol Biomarkers Prev 2004; 13: 765-70.

41 Kumle M, Weiderpass E, Braaten T, Adami H-O, Lund E. Risk of invasive and borderline epithelial ovarian neoplasias following use of hormonal contraceptives: the Norwegian-Swedish Women's Lifestyle and Health Cohort Study. Br J Cancer 2004; 90: 1386-91.

42 Pike MC, Pearce CL, Peters R, Cozen W, Wan P, Wu AH. Hormonal factors and the risk of invasive ovarian cancer: a population-based case-control study. Fertil Steril 2004; 82: 186-95.

43 Rossing MA, Tang M-TC, Flagg EW, Weiss LK, Wicklund KG. A case-control study of ovarian cancer in relation to infertility and the use of ovulation inducing drugs. Am J Epidemiol 2004; 160: 1070-78.

44 Zhang M, Lee AH, Binns CW. Reproductive and dietary risk factors for epithelial ovarian cancer in China. Gynecol Oncol 2004; 92: 320-26.

45 Doody MM, Freedman DM, Alexander BH, et al Breast cancer in US radiologic technologists. Cancer 2006; 106: 2707-15.

46 Mommers M, Schouten LJ, Goldbohm RA, van den Brandt PA. Dairy consumption and ovarian cancer risk in the Netherlands Cohort Study on Diet and Cancer. Br J Cancer 2006; 94: 165-70.

47 Patel AV, Rodriguez C, Pavluck AL, Thun MJ, Calle EE. Recreational physical activity and sedentary behaviour in relation to ovarian cancer risk in a large cohort of US women. Am J Epidemiol 2006; 163: 709-16.

48 Koch M, Jenkins H, Gaedke H. Risk factors of ovarian cancer of epithelial origin: a case-control study. Cancer Detect Prev 1988, 13: 131-36.

49 Chen Y, Wu PC, Lang JH, GE W-J, Hartge P, Brinton LA. Risk factors for epithelial ovarian cancer in Beijing, China. Int J Epidemiol 1992; 21: 23-29.
50 Shushan A, Paltiel O, Iscovich J, Elchalal U, Peretz T, Schenter JG. Human menopausal gonadotropin and the risk of epithelial ovarian cancer. Fertil Steril 1996; 65: 13-18

51 WHO. International Classification of Diseases, 10th edn. Geneva: World Health Organisation, 1994

52 Coulter A, Vessey M, McPherson K. The ability of women to recall their oral contraceptive use. Contraception 1986; 33: 127-37.

53 Piper JM, Kennedy DL. Oral contraceptives in the United States: trends in content and potency. Int J Epidemiol 1987; 16: 215-21.

54 Thorogood M, Villard-Mackintosh L. Combined oral contraceptives: risks and benefits. Br Med Bull 1993; 49: 124-39.

55 Collaborative Group on Hormonal Factors in Breast Cancer. Breast cancer and hormonal contraceptives: further results. Contraception 1996; 54: 1S-106S

56 Peto R, Pike M, Armitage P, et al. Design and analysis of randomized clinical trials requiring prolonged observation of each patient. I: introduction and design. Br J Cancer 1976; 34: 585-612.

57 Peto R, Pike M, Armitage P, et al. Design and analysis of randomized clinical trials requiring prolonged observation of each patient. II: analysis and examples. Br J Cancer 1977; 35: 1-39.

58 Easton DF, Peto J, Babiker AGAG. Floating absolute risk: an alternative to relative risk in survival and case-control analysis avoiding an arbitrary reference group. Stat Med 1991; 10: 1025-35.

59 Peto R, Lopez AD, Boreham J, Thun M, Heath C. Mortality from smoking in developed countries 1950-2000. Oxford: Oxford University Press, 1995.

60 International Agency for Research on Cancer. http://www-dep.iarc. fr (accessed June 23, 2007).

61 Population Reference Bureau. www.prb.org/Publications/Data sheets/2002/FamilyPlanningWorldwide (accessed June 23, 2007)

62 Bongaarts J, Johansson E. Future trends in contraceptive prevalence and method mix in the developing world. Stud Fam Plann 2002; 33: $24-36$. 